\title{
Rapid identification of candida species by TaqMan PCR
}

\author{
M Guiver, K Levi, B A Oppenheim
}

\begin{abstract}
Aim-To develop and evaluate a TaqMan $^{\text {TM }}$ polymerase chain reaction (PCR) for the rapid identification and speciation of candida species.

Methods-Species specific primer and probe sets were designed for the identification of Candida albicans, $C$ parapsilosis, C tropicalis, C krusei, C kefyr, and $C$ glabrata from clinical isolates in a $5^{\prime}$ exonuclease (TaqMan ${ }^{\mathrm{TM}}$ ) assay. The probes were labelled with three fluorescent dyes to enable differentiation between species when three primer and probe sets were combined in two multiplexes. The specificity of these assays was evaluated against a range of National Collection of Pathogenic Fungi strains, clinical isolates of yeast, bacterial and viral pathogens.

Results-The primer and probe sets have been shown to be $100 \%$ specific for their respective species; there was no crossreaction between any set and human DNA, or extracts from other candida species, fungal, bacterial, or viral pathogens tested. Extracts from two clinical isolates, originally identified as $C$ albicans on the basis of germ tube formation, were not amplified by any of the primer and probe sets. These isolates have been putatively re-identified as $C$ dubliniensis after sequencing of the variable internal transcribed spacer region ITS 2 and lack of growth at $45^{\circ} \mathrm{C}$.

Conclusion-This TaqMan assay provides a rapid alternative to conventional culture based techniques for the identification and speciation of the most frequently isolated candida species. The simple extraction method followed by TaqMan PCR can identify the six species mentioned in four hours.

(F Clin Pathol 2001;54:362-366)
\end{abstract}

Keywords: candida identification; TaqMan ${ }^{\mathrm{TM}}$; polymerase chain reaction

Manchester Public Health Laboratory, Withington Hospital, Manchester M20 2LR, UK

M Guiver

K Levi

B A Oppenheim

Correspondence to: Dr Guiver

mguiver@nw.phls.nhs.uk

Accepted for publication 22 October 2000

antibiotics. ${ }^{1-3}$ Long term treatment with amphotericin and fluconazole has led to antifungal drug resistance in Candida albicans and an increase in non-albicans candida infections. Certain yeast species, such as $C$ krusei, are intrinsically resistant to fluconazole, and isolates of $C$ glabrata and $C$ tropicalis may become resistant. ${ }^{4}$ Thus, rapid speciation of candida isolates allows appropriate clinical decisions to be made concerning targeted antifungal treatment and its dosage and duration.

The identification of candida isolates to the species level using carbohydrate assimilation protocols $^{5}$ can be problematic, although primary isolation using CHROMagar can be used with reasonable specificity for rapid identification. Pan-fungal PCR assays have been evaluated for the detection of a broad spectrum of species, ${ }^{67}$ as have candida specific primers ${ }^{8}$ and $C$ albicans specific and pan-fungal primers in conjunction with species specific probes. ${ }^{5-11}$

In this approach, species specific primers and fluorescent probes have been designed for a $5^{\prime}$ exonuclease ( $\operatorname{TaqMan}^{\mathrm{TM}}$ ) assay for the six most clinically important candida species, namely: $C$ albicans, $C$ parapsilosis, $C$ tropicalis, $C$ krusei, $C$ kefyr, and $C$ glabrata. ${ }^{12}$ The primer/ probe sets can be used individually or combined in two multiplex sets. Species can be differentiated within the multiplex by the use of three spectrally distinct fluorescent reporter dyes (FAM (6-carboxy-fluorescein), TET (tetrachloro-6-carboxy-fluorescein), or VICTM) attached to the $5^{\prime}$ end of the probes.

The TaqMan 5' exonuclease assay is a homogenous system using a fluorescent labelled probe for the detection of PCR product in "real time". This provides a rapid automated combined PCR amplification and detection system with no postamplification manipulation of amplicons, thereby considerably reducing the risk of contamination. Coupled with a quick, simple DNA extraction method, this protocol allows rapid speciation of clinical isolates. Testing time is reduced from a mean of 3.5 days after the isolation of a yeast isolate ${ }^{10}$ to four hours by the TaqMan ${ }^{\mathrm{TM}}$ procedure.

\section{Material and methods}

BACTERIAL AND FUNGAL STRAINS

Fungal type strains were obtained from the National Collection of Pathogenic Fungi (NCPF, Public Health Laboratory Service (PHLS), Bristol) (tables 1 and 2). Fungal and bacterial clinical isolates used were obtained from the bacteriology and mycology departments of the PHLS, Manchester. Clinical isolates were identified by morphological and biochemical tests. Yeast species were also identified by means of the carbohydrate assimilation test API 20 Candida (BioMerieux, Lyon, France).
DNA EXTRACTION

Yeast and Gram positive bacterial strains

DNA was extracted from overnight yeast colonies grown on Sabouraud medium at $30^{\circ} \mathrm{C}$. 
Table 1 Species specific TaqMan ${ }^{\mathrm{TM}}$ primer and probe sequences and fluorescent labels

\begin{tabular}{|c|c|c|}
\hline Species & \multicolumn{2}{|r|}{ 5' to 3' primer and probe sequences and probe label } \\
\hline \multicolumn{3}{|l|}{ Multiplex A } \\
\hline \multirow[t]{3}{*}{ Candida albicans } & $\mathrm{F}$ & GGG TTT GCT TGA AAG ACG GTA \\
\hline & $\mathrm{R}$ & TTG AAG ATA TAC GTG GTG GAC GTT A \\
\hline & $\mathrm{P}$ & FAM-ACC TAA GCC ATT GTC AAA GCG ATC CCG \\
\hline \multirow[t]{3}{*}{$C$ kefyr } & $\mathrm{F}$ & GGC TGC GTG TCG AGT CTA TG \\
\hline & $\mathrm{R}$ & TGA CCC AAG CTT ACC ACG AAT \\
\hline & $\mathrm{P}$ & TET-ACT CTT GCA CAT CTA CGT CTT AGG TTT GCG C \\
\hline \multirow[t]{3}{*}{ C glabrata } & $\mathrm{F}$ & TTT CTC CTG CCT GCG CTT AA \\
\hline & $\mathrm{R}$ & ACG CAC ACT CCC AGG TCT TT \\
\hline & $\mathrm{P}$ & VIC-AGA ACA CCC ACC AAC CGC GCA \\
\hline \multicolumn{3}{|l|}{ Multiplex B } \\
\hline \multirow[t]{3}{*}{ C parapsilosis } & $\mathrm{F}$ & GGG TTT GGT GTT GAG CGA TAC \\
\hline & $\mathrm{R}$ & GGA GTT TGT ACC AAT GAG TGG AAA \\
\hline & $\mathrm{P}$ & FAM-CTC CGC CTT TCT TTC AAG CAA ACC CAG \\
\hline \multirow[t]{3}{*}{ C tropicalis } & $\mathrm{F}$ & CGT GGT AAC TTA TTT TAA GCG \\
\hline & $\mathrm{R}$ & GCT TAA GTT CAG CGG GTA GTC CTA \\
\hline & $\mathrm{P}$ & TET-TGG CCA CCA TTT ATT TCA TAA CTT TGA CC \\
\hline \multirow[t]{3}{*}{ C krusei } & $\mathrm{F}$ & GCT GCG ACT CGC CTG AA \\
\hline & $\mathrm{R}$ & TTG TCT CGC AAC ACT CGC TCT \\
\hline & $\mathrm{P}$ & VIC-CTA GTT CGC TCG GCC AGC TTC GCT \\
\hline
\end{tabular}

Probe labels are highlighted in bold.

$\mathrm{F}$, forward primer; R, reverse primer; $\mathrm{P}$ probe (phosphorylated at the $3^{\prime}$ end).

Single colonies were suspended in $1 \mathrm{ml}$ sterile water and adjusted photometrically to an optical density of 0.1 at $\mathrm{A}_{650}$. Gram positive bacterial cultures were suspended in sterile water and adjusted to approximately $2 \times 10^{4}$ colony forming units $(\mathrm{CFU}) / \mathrm{ml}$ by carrying out Miles and Misra viable counts for each of the bacterial isolates, and the concentrations adjusted accordingly. DNA was extracted by adding $100 \mu \mathrm{l}$ of these dilutions to $1 \mathrm{ml} \mathrm{DNAzol}{ }^{\mathrm{TM}}$ solution (Life Technologies, Glasgow, UK), vortexing, and incubation at room temperature for 10 minutes. DNA was precipitated by adding $1 \mathrm{ml}$ ethanol and centrifuging at $12000 \times g$ for 10 minutes. The pellet was washed with $1 \mathrm{ml}$ ethanol and resuspended in $50 \mu \mathrm{l}$ sterile water.

Gram negative bacterial strains

Five colonies from an overnight culture were suspended in $500 \mu \mathrm{l}$ sterile water and heated at $99^{\circ} \mathrm{C}$ for 10 minutes. The samples were transferred to $-20^{\circ} \mathrm{C}$ for one minute to denature the DNA and were then centrifuged at $12000 \times g$ for 10 minutes. The supernatant was used directly as a PCR template.

\section{Aspergillus strains}

Aspergillus strains were incubated at $30^{\circ} \mathrm{C}$ on Sabouraud medium for 72 hours. Conidia were harvested into $0.01 \%$ Tween 20 . DNA extraction was carried out according to Einsele et al, with minor modifications. ${ }^{6}$ A $1 \mathrm{ml}$ sample, containing $10^{5}-10^{6} \mathrm{CFU}$, was incubated with $5 \mathrm{ml}$ white cell lysis buffer $(10 \mathrm{mM}$ Tris/ $\mathrm{HCl}$ (pH 7.4), 10 mM EDTA (pH 8.0), $50 \mathrm{mM}$ $\mathrm{NaCl}, 0.2 \%$ lauryl sulphate, $200 \mu \mathrm{g}$ proteinase $\mathrm{K} / \mathrm{ml}$ (Sigma, Poole, UK)) at $65^{\circ} \mathrm{C}$ for two hours. After centrifugation for 15 minutes at $1500 \times g, 5 \mathrm{ml}$ of supernatant was removed and discarded. The remaining $1 \mathrm{ml}$ was transferred to a microcentrifuge tube and spun at $12000 \times g$ for 10 minutes. The pellet was resuspended in $50 \mathrm{mM} \mathrm{NaOH}$ and incubated at $95^{\circ} \mathrm{C}$ for 10 minutes. After centrifugation at $5000 \times g$ for 10 minutes the pellet was treated with $500 \mu \mathrm{l}$ zymolase buffer $(50 \mathrm{mM}$ Tris/ $\mathrm{HCl}$ (pH 7.4), $\quad 10 \mathrm{mM} \quad$ EDTA, $28 \mathrm{mM}$ $\beta$-mercaptoethanol, $300 \mu \mathrm{g}$ zymolase/ml (ICN
Table 2 Species tested against all primer/probe sets

\begin{tabular}{|c|c|}
\hline Species & $\begin{array}{l}\text { TaqMan } \\
\text { result }\end{array}$ \\
\hline Candida albicans NCPF 3153 & C albicans + \\
\hline$C$ albicans NCPF 3281 & C albicans + \\
\hline$C$ albicans NCPF 8154 & C albicans + \\
\hline$C$ albicans NCPF 8154 & Calbicans + \\
\hline C tropicalis NCPF 3111 & C tropicalis + \\
\hline C tropicalis NCPF 8113 & C tropicalis + \\
\hline C tropicalis NCPF 8156 & C tropicalis + \\
\hline C tropicalis NCPF 3980 & C tropicalis + \\
\hline C tropicalis NCPF 8157 & C tropicalis + \\
\hline C parapsilosis NCPF 3104 & $C$ parapsilosis + \\
\hline C parapsilosis NCPF 3938 & C parapsilosis + \\
\hline$C$ krusei NCPF 3100 & C krusei + \\
\hline C krusei NCPF 3930 & C krusei + \\
\hline C krusei NCPF 3953 & C krusei + \\
\hline C kefyr NCPF 3106 & $C$ kefyr + \\
\hline C glabrata NCPF 3309 & C glabrata + \\
\hline C glabrata NCPF 8018 & C glabrata + \\
\hline C glabrata $\mathrm{NCPF} 3943$ & C glabrata + \\
\hline C glabrata NCPF 8155 & C glabrata + \\
\hline C lusitaniae NCPF 3833 & Negative \\
\hline C pelliculosa NCPF 3356 & Negative \\
\hline C zeylanoides NCPF 3871 & Negative \\
\hline$C$ viswanathiae NCPF 3151 & Negative \\
\hline C dubliniensis NCPF 3949 & Negative \\
\hline Saccharomyces cerevisiae NCPF 3178 & Negative \\
\hline Aspergillus fumigatus NCPF 2109 & Negative \\
\hline A flavus NCPF 2008 & Negative \\
\hline A terreus NCPF 2026 & Negative \\
\hline$A$ niger $\mathrm{NCPF} 2275$ & Negative \\
\hline A nidulans NCPF 2691 & Negative \\
\hline$A$ versicolor $\mathrm{NCPF} 7246$ & Negative \\
\hline Neisseria meningitidis $(\mathrm{n}=2)$ & Negative \\
\hline N lactamica $(\mathrm{n}=1)$ & Negative \\
\hline N gonorrhoeae $(\mathrm{n}=1)$ & Negative \\
\hline Methicillin resistant Staphylococcus aureus $(\mathrm{n}=3)$ & Negative \\
\hline Coagulase negative staphylococci $(\mathrm{n}=3)$ & Negative \\
\hline Group B streptococci $(\mathrm{n}=3)$ & Negative \\
\hline Streptococcus pneumoniae $(\mathrm{n}=3)$ & Negative \\
\hline Escherichia coli $(\mathrm{n}=3)$ & Negative \\
\hline Moraxella cattharralis $(\mathrm{n}=3)$ & Negative \\
\hline Pseudomonas aeruginosa $(\mathrm{n}=3)$ & Negative \\
\hline Diptheroids $(n=3)$ & Negative \\
\hline Enterococcus faecalis $(\mathrm{n}=5)$ & Negative \\
\hline Acinetobacter $(n=3)$ & Negative \\
\hline Klebsiella aerogenes $(\mathrm{n}=3)$ & Negative \\
\hline Haemophilus influenzae $(\mathrm{n}=3)$ & Negative \\
\hline Proteus mirabilis $(\mathrm{n}=3)$ & Negative \\
\hline Cytomegalovirus $(\mathrm{n}=3)$ & Negative \\
\hline Varicella zoster virus $(n=1)$ & Negative \\
\hline Herpes simplex virus $(n=3)$ & Negative \\
\hline
\end{tabular}

Biomedicals, Ohio, USA)) at $37^{\circ} \mathrm{C}$ for 45 minutes. The spheroplast solution was pelleted at $5000 \times g$ for 10 minutes. The extraction procedure was completed according to the manufacturer's instructions for the tissue protocol included in the QIAamp DNA mini kit (Qiagen, Crawley, UK) and was eluted from the spin column using the supplied AE elution buffer.

Human genomic DNA extraction

DNA was extracted from whole blood from a healthy volunteer with the Generation ${ }^{\mathrm{TM}}$ Capture Column ${ }^{\mathrm{TM}}$ kit (Gentra Systems, Minneapolis, USA), according to the manufacturer's instructions.

Viral extracts

DNA was extracted from $100 \mu$ of hepatitis B positive serum and herpes simplex virus and varicella zoster virus tissue culture fluid by the addition of $1 \mathrm{ml}$ DNAzol solution (Life Technologies), vortexing, and incubation at room temperature for 10 minutes. DNA was precipitated by adding $1 \mathrm{ml}$ ethanol and centrifuging at $12000 \times g$ for 10 minutes. The pellet was washed with $1 \mathrm{ml}$ ethanol and resuspended in $50 \mu 1$ sterile water. 
DNA was extracted from blood samples from cytomegalovirus positive patients according to the instructions of the Generation Capture Column kit (Gentra Systems).

SPECIFICITY

A range of fungal bacterial and viral pathogens was evaluated in specificity tests with all candida primer and probe sets (table 2). In addition, the amplification of human genomic DNA, extracted from whole blood, was assessed.

PRIMERS AND PROBES

Oligonucleotide primer and probe sets were designed from the variable internal transcribed spacer region ITS $2^{13}{ }^{14}$ for the specific amplification of $C$ albicans, $C$ tropicalis, $C$ parapsilosis, $C$ krusei, $C$ kefyr, and $C$ glabrata (table 1) using the Primer Express program (PE-ABI, Foster City, California, USA). Primers and probes were synthesised by PE-ABI (Warrington, UK); TaqMan probes were synthesised with one of three reporter dyes (FAM, TET, or VIC) (table 1) covalently linked to the 5' end and the quencher dye TAMRA (6carboxytetremethylrhodamine) at the $3^{\prime}$ ends. The 3 ' ends were phosphorylated to prevent extension of the probe.

AMPLIFICATION USING THE PERKIN-ELMER APPLIED BIOSYSTEMS (PE-ABI) 7700 SEQUENCE DETECTION SYSTEM

The $25 \mu$ reaction contained $2 \mu$ l extracted sample with $12.5 \mu 1$ TaqMan PCR Universal Master Mix (PE-ABI), $0.2 \mu \mathrm{M}$ each primer, and $0.1 \mu \mathrm{M}$ probe. In multiplex, the FAM and TET labelled probe concentrations were reduced to $50 \mathrm{nM}$. DNA amplification was carried out in 96 well microtitre plates sealed with MicroAmp optical caps (PE-ABI). The cycling programme on the PE-ABI 7700 sequence detection system consisted of heating for two minutes at $50^{\circ} \mathrm{C}$ and $95^{\circ} \mathrm{C}$ for $10 \mathrm{~min}-$ utes, which preceded a two stage temperature profile of $95^{\circ} \mathrm{C}$ for 15 seconds and $60^{\circ} \mathrm{C}$ for one minute, repeated for 45 cycles. Data points collected at the end of each extension stage were analysed at the end of thermal cycling. During the first 15 cycles, data are collected from all wells and the background fluorescence is determined. A threshold value is calculated as 10 SD above the mean background fluorescence. A sample is considered positive if the fluorescence signal crosses this threshold within 45 cycles; the cycle number at which this occurs is recorded as the $\mathrm{C}_{\mathrm{T}}$ value.
SEQUENCING OF THE ITS2 REGION

The $100 \mu \mathrm{l}$ reaction was composed of $1.5 \mathrm{mM}$ $\mathrm{MgCl}_{2}, 200 \mu \mathrm{M}$ dNTPs, $500 \mathrm{nM}$ each primer (ITS3 and ITS4), ${ }^{9}$ and $2.5 \mathrm{U}$ Taq DNA polymerase (Life Technologies) with the manufacturer's PCR buffer $(20 \mathrm{mM}$ Tris/ $\mathrm{HCl}$ (pH 8.4), $50 \mathrm{mM} \mathrm{KCl}$ ) and $0.05 \%(\mathrm{vol} / \mathrm{vol})$ of detergent W-1. The cycling programme was carried out in an automated thermal cycler (PTC 200 DNA Engine; MJ Research, Massachusetts, USA) and comprised denaturation at $94^{\circ} \mathrm{C}$ for one minute, followed by 35 cycles of $94^{\circ} \mathrm{C}$ for 30 seconds, $55^{\circ} \mathrm{C}$ for 30 seconds, and $72^{\circ} \mathrm{C}$ for 30 seconds. The final extension step was five minutes at $72^{\circ} \mathrm{C}$. Amplicons were visualised on a $2 \%$ TBE gel, stained with ethidium bromide. PCR products were purified with GFX ${ }^{\mathrm{TM}}$ PCR DNA and Gel Band purification kit (Amersham Pharmacia Biotech, St Albans, UK), according to the manufacturer's instructions. Cycling sequencing was performed for 25 cycles of $95^{\circ} \mathrm{C}$ for 30 seconds, $50^{\circ} \mathrm{C}$ for 15 seconds, and $60^{\circ} \mathrm{C}$ for four minutes using Big Dye reaction mix (PE$\mathrm{ABI})$. After ethanol precipitation, automated sequencing was performed on an ABI 310 Genetic Analyser (PE-ABI) using the ITS3 and ITS4 primers.

\section{Results}

SPECIFICITY OF TaqMan PRIMER AND PROBE SETS Six primer/probe sets were designed for the specific identification of $C$ albicans, $C$ tropicalis, $C$ parapsilosis, $C$ krusei, $C$ kefyr, and $C$ glabrata (table 1). They were tested in a TaqMan assay against a range of NCPF candida strains and other fungal, bacterial, and viral pathogens (table 2). The primer/probe sets correctly identified $100 \%$ of NCPF strains without crossreaction with DNA from heterologous species (table 3 ). None of the six sets amplified DNA isolated from human whole blood.

SPECIFICITY OF TaqMan PRIMER AND PROBE SETS FOR CLINICAL ISOLATES

DNA extracts from a total of 80 clinical isolates were analysed with the TaqMan candida primer and probe sets (table 4 ). The $C$ tropicalis, $C$ parapsilosis, $C$ krusei, $C$ kefyr and $C$ glabrata sets correctly identified all the isolates previously identified as these species. There was no crossreaction of any of the candida sets with Clusitaniae, C famata, or Cryptococcus neoformans isolates. One Saccharomyces cerevisiae isolate was identified as $C$ parapsilosis with the TaqMan assay. Subsequent testing of this isolate revealed that it was a mixed culture of

Table 3 Specificity of candida primer and probe sets tested against NCPF strains and clinical isolates

\begin{tabular}{lllllll}
\hline \multicolumn{5}{c}{ Mean $C_{T}$ value $(S E)$} & & \\
\cline { 2 - 7 } Sample DNA & Candida albicans & C parapsilosis & C tropicalis & C krusei & C kefyr & C glabrata \\
\hline C albicans $(\mathrm{n}=11)$ & $27.18(0.86)$ & 45 & 45 & 45 & 45 & 45 \\
C parapsilosis $(\mathrm{n}=13)$ & 45 & $27.46(1.57)$ & 45 & 45 & 45 & 45 \\
C tropicalis $(\mathrm{n}=14)$ & 45 & 45 & $28.34(0.63)$ & 45 & 45 & 45 \\
C krusei $(\mathrm{n}=12)$ & 45 & 45 & 45 & $26.23(0.43)$ & 45 & 45 \\
C kefyr $(\mathrm{n}=4)$ & 45 & 45 & 45 & 45 & $28.00(2.47)$ & 45 \\
C glabrata $(\mathrm{n}=16)$ & 45 & 45 & 45 & 45 & 45 & $26.89(0.55)$
\end{tabular}

NCPF, National Collection of Pathogenic Fungi. 
Table 4 Identification of clinical isolates by candida TaqMan ${ }^{\mathrm{TM}}$ assay

\begin{tabular}{|c|c|c|}
\hline Mycology identification & TaqMan result & Final identification \\
\hline Candida albicans $(\mathrm{n}=16)$ & $\begin{array}{l}\text { C albicans } 14 / 16 \\
\text { Negative } 2 / 16\end{array}$ & $\begin{array}{l}C \text { albicans } 14 / 16 \\
C \text { dubliniensis }{ }^{\star} 2 / 16\end{array}$ \\
\hline C tropicalis $(\mathrm{n}=12)$ & $C$ tropicalis $12 / 12$ & C tropicalis $12 / 12$ \\
\hline$C$ parapsilosis $(\mathrm{n}=13)$ & C parapsilosis $13 / 13$ & $C$ parapsilosis $13 / 13$ \\
\hline Ckrusei $(\mathrm{n}=10)$ & $C$ krusei $10 / 10$ & C krusei $10 / 10$ \\
\hline$C$ kefyr $(\mathrm{n}=3)$ & $C$ kefyr $3 / 3$ & $C$ kefyr $3 / 3$ \\
\hline$C$ glabrata $(\mathrm{n}=12)$ & $C$ glabrata $12 / 12$ & C glabrata $12 / 12$ \\
\hline \multirow[t]{2}{*}{ Saccharomyces cerevisiae $(\mathrm{n}=10)$} & Negative $9 / 10$ & $S$ cerevisiae $9 / 10$ \\
\hline & $C$ parapsilosis $1 / 10$ & $\begin{array}{l}S \text { cerevisiae }+ \\
C \text { parapsilosis } 1 / 10\end{array}$ \\
\hline Cryptococcus neoformans $(\mathrm{n}=1)$ & Negative $1 / 1$ & Cryptococcus neoformans $1 / 1$ \\
\hline C lusitaniae $(\mathrm{n}=1)$ & Negative $1 / 1$ & C lusitaniae $1 / 1$ \\
\hline C famata $(\mathrm{n}=2)$ & Negative $2 / 2$ & $C$ famata $2 / 2$ \\
\hline
\end{tabular}

Mycology identification: identification was based on API 20C and germ tube formation for $C$ albicans.

${ }^{\star}$ Putative identification based on sequencing of the internal transcribed spacer region ITS2 region, germ tube formation, chlamydospore production, and lack of growth at $45^{\circ} \mathrm{C}$

$S$ cerevisiae and $C$ parapsilosis. This result demonstrates that the specificity of the assay is not compromised by mixed culture isolates.

Two isolates identified as $C$ albicans as a result of germ tube formation and chlamydospore production were negative with all the specific primer and probe sets. Nucleotide sequence analysis of the ITS2 region was undertaken and comparison of this sequence with the ITS2 region from $C$ dubliniensis (accession number U96719) showed 100\% homology. The combination of these data, the lack of growth at $45^{\circ} \mathrm{C}$ of both isolates, and presence of chlamydospores and germ tubes enabled re-identification of both isolates as $C$ dubliniensis.

\section{Discussion}

The prevalence of candida infection and the rise in species resistant to polyene and azole drugs means that rapid speciation of isolates has become increasingly important for targeted treatment. This is the first report of the use of species specific primers and probes in a rapid $5^{\prime}$ exonuclease format for the detection of the six most clinically important candida species from clinical isolates. The primer and probe sets have been shown to have $100 \%$ specificity for their respective species, with no crossreaction with DNA extracts from other candida species, whole blood, or other fungal, bacterial, and viral species tested. This assay is currently being evaluated in our laboratory for the detection of candida species directly from clinical samples and, therefore, it was important to ensure during this evaluation that there was no crossreaction with other bacteria and viruses likely to be present in such samples. The assay combines a simple, rapid, and non-toxic (no phenol/chloroform) DNA extraction with TaqMan amplification. The latter is a "real time" PCR format; therefore, no postamplification detection is necessary. The six primer and probe sets are combined into two multiplex reactions with each of the species specific probes labelled with a spectrally distinct fluorescent dye. The amplified species from the multiplex reaction can therefore be identified without further testing.

In our study, species specific primer pairs have been used in conjunction with species specific probes. Previously described methods have combined pan-fungal primers with species specific probes for the detection of candida species. $^{5-11}$

The pan-fungal approach has led to specificity problems in some cases: Einsele and colleagues ${ }^{6}$ noted crossreactions between the probe for $C$ glabrata and $C$ tropicalis DNA and between the $C$ krusei probe and $C$ parapsilosis extracts. A matrix system of probe hybridisation was used to differentiate between crossreacting species. Non-specific hybridisation of $C$ glabrata probes with $S$ cerevisiae DNA has also been noted. ${ }^{9} 10$ In addition, Elie and colleagues $^{10}$ observed crossreaction between their $C$ albicans probe and DNA from $C$ stellatoidea, although the separate status of type I $C$ stellatoidea from $C$ albicans has been questioned. ${ }^{15} \mathrm{~A}$ candida specific probe was shown to hybridise with ITS 3 and ITS4 amplified products from $S$ cerevisiae, Aspergillus fumigatus, and A flavus, necessitating further analysis with aspergillus and $S$ cerevisiae probes. ${ }^{11}$

The presence of two putative $C$ dubliniensis clinical isolates, originally identified as $C$ albicans on the basis of germ tube formation and chlamydospore production, was highlighted by the absence of amplification with the $C$ albicans primer and probe set. Germ tube formation, abundant chlamydospore production, lack of growth at $45^{\circ} \mathrm{C}$, and sequence analysis of the ITS2 region amplified from these samples resulted in their suggested identification. ${ }^{16}{ }^{17}$ Germ tube positive isolates are assumed to be $C$ albicans in our laboratory; however, it might be useful to distinguish $C$ dubliniensis species, which may rapidly develop resistance to fluconazole. ${ }^{18}$ We are currently evaluating a $C d u b-$ liniensis specific primer and probe set.

This assay allows rapid speciation of isolates of $C$ albicans, $C$ parapsilosis, $C$ tropicalis, $C$ krusei, $C$ kefyr, and $C$ glabrata to be undertaken in four hours, compared with a mean of 3.5 days reported for conventional phenotypic tests. ${ }^{10}$ The estimated consumable cost for this assay is about $£ 2.00$, compared with $£ 1.55$ for the cost of a CHROMagar plate, although considerable capital investment is required for the PE-ABI 7700 Sequence Detection system.

In a routine laboratory, this approach could be focused on the rapid identification of candida isolates from high risk patient groups-for example, bone marrow transplant recipients, other patients on intensive immunosuppressive regimens, and patients in intensive treatment units-where this information may guide prompt and appropriate treatment. The effectiveness of this assay for the direct identification of candida species from blood culture or clinical samples is currently being evaluated.

1 Jarvis WR. Epidemiology of nosocomial fungal infections, with emphasis on candida species. Clin Infect Dis 1995;20:1526-30.

2 Fridkin SK, Jarvis WR. Epidemiology of nosocomial fungal infections. Clin Microbiol Rev 1996;9:499-511.

3 White TC, Marr KA, Bowden RA. Clinical, cellular and molecular factors that contribute to antifungal drug resistance. Clin Microbiol Rev 1998;11:382-402.

4 Vanden Bossche H, Dromer F, Improvis I, et al. Antifungal drug resistance in pathogenic fungi. Med Mycol 1998;36: 19-28. 
5 Ainscough S, Kibbler CC. An evaluation of the costeffectiveness of using CHROMagar for yeast identification in a routine microbiology laboratory. $\mathcal{F}$ Med Microbiol 1998; in a routine

6 Einsele H, Hebart H, Roller G, et al. Detection and identification of fungal pathogens in blood by using molecular probes. F Cin Microbiol 1997;35:1353-60.

7 van Burik J-A, Myerson D, Schreckhise RW, et al. Panfungal PCR assay for detection of fungal infection in human blood samples. F Clin Microbiol 1998;36:1169-75.

8 van Deventer AJM, Goessens WHF, van Belkum A, et al. Improved detection of Candida albicans by PCR in blood of neutropenic mice with systemic candidiasis $\mathcal{F}$ Clin Microbiol 1995;33:625-8.

9 Fujita S-I, Lasker BA, Lott TJ, et al. Microtitration plate enzyme immunoassay to detect PCR-amplified DNA from

10 Elie CM, Lott TJ, Reiss E, al al. Rapid identification of candida species with species-specific DNA probes. F Clin

11 Shin JH, Nolte FS, Holloway BP, et al. Rapid identification of up to three candida species in a single reaction tube by a 5' exonuclease assay using fluorescent DNA probes. $\mathcal{F}$ Clin
12 Murray PR, Rosenthal KS, Kobayashi GS, et al. Opportunistic mycoses. In: Medical microbiology. St Louis: MosbyYear Book Inc, 1998 .

13 Lott TJ, Kuykendall RJ, Reiss E. Nucleotide sequence analysis of the $5.8 \mathrm{~S} \mathrm{rDNA}$ and adjacent ITS2 region of Candida albicans and relates species. Yeast 1993;9:1199206.

14 Lott TJ, Burns BM, Zancope-Oliveira R, et al. Sequence analysis of the internal transcribed spacer 2 (ITS2) from yeast species within the genus candida. Curr Microbiol 1998;36:63-9.

15 McCullough MJ, Clemons KV, Stevens DA. Molecular and phenotypic characterization of genotypic Candida albicans subgroups and comparison with Candida dubliniensis and Candida stellatoidea. $\mathcal{F}$ Clin Microbiol 1999;37:417-21.

16 Sullivan D, Coleman D. Candida dubliniensis: characteristics and identification. F Clin Microbiol 1998;36:329-34.

17 Odds FC, van Nuffel L, Dams G. Prevalence of Candida dubliniensis isolates in a yeast stock collection. $f$ Clin Microbiol 1998;36:2869-73.

18 Jabra-Rizk MA, Baqui AAMA, Kelley JI, et al. Identification of Candida dublinienisis in a prospective study of patients in the United States. F Clin Microbiol 1999;37:321-6.

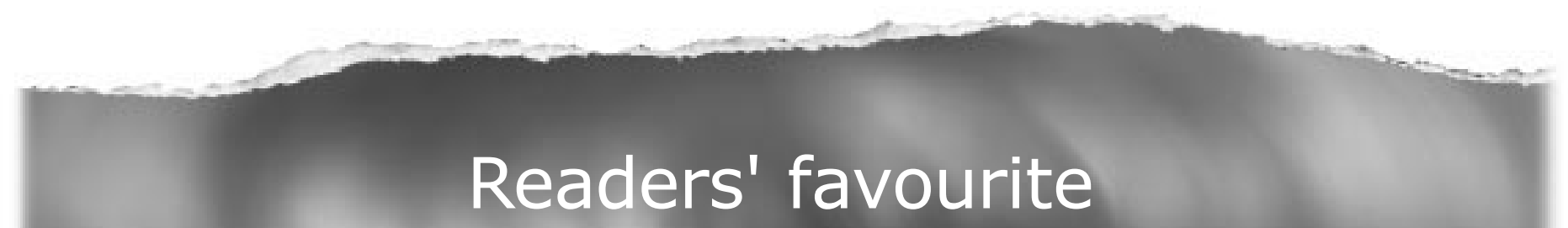

Top 10

Click on the "Top 10" button on the homepage to see which are the best read articles each month

www.jclinpath.com 